\title{
Bağlamsal Pazarlama: Avantajları, Zorlukları ve Stratejileri Üzerine Kavramsal Bir Değerlendirme*
}

\section{Contextual Marketing: A Conceptual Assessment of Its Advantages, Challenges, and Strategies}

\author{
Yasemin GEDik ${ }^{1}$
}

\begin{abstract}
$\ddot{O} z$
Günümüzde, teknolojinin hızla gelişimi ve internetin günlük yaşamın her alanına derinden nüfuz etmesi tüketici davranışında büyük değişimlere sebep olmaktadır. İşletmeler, bir bireyin durumuna ve ihtiyaçlarına göre kişiselleştirilmiş içerik sağlayarak genel müşteri deneyimini geliştirmeye odaklanmaktadır. Bağlamsal pazarlama, doğru bilgileri, doğru zamanda ve doğru kişilere ulaştırmaya dayanan etkili bir pazarlama aracıdır. Bağlamsal pazarlama işletmelere, uygun maliyetle daha başarılı hedefleme, potansiyel müşterileri aktif müşterilere dönüştürmek, satışları ve marka farkındalığını arttırmak, geleneksel reklamcılığın tüketiciyi kesintiye uğratan konseptini yok etmek gibi çok sayıda fayda sağlamaktadır. Bununla birlikte, literatürde bağlamsal pazarlama hakkında yapılan çalışmalar oldukça kısıtlıdır ve bu alanda çok daha fazla araştırmaya ihtiyaç bulunmaktadır. Bu çalışma, bağlamsal pazarlama ilgili geniş bir teorik çerçeve oluşturmaya odaklanmaktadır. Ayrıca çalışma, konuyla ilgili güncel istatistikler ve bağlamsal pazarlama stratejilerini de inceleyerek ilgili kararları alırken işletme yöneticilerine yardımcı olmayı amaçlamaktadır.

Anahtar Kelimeler : Bağlam, Hedefleme, Bağlamsal pazarlama, Bağlamsal reklamcllk
\end{abstract}

\begin{abstract}
Today, the rapid development of technology and the deep penetration of the internet into every aspect of daily life cause great changes in consumer behavior. Businesses focus on improving the overall customer experience by providing personalized content based on an individual's situation and needs. Contextual marketing is an effective marketing tool based on delivering the right information to the right people at the right time. Contextual marketing provides many benefits such as targeting more successfully at affordable cost, converting potential customers into active customers, increasing sales and brand awareness, and eliminating the disruptive concept of traditional advertising. However, studies on contextual marketing in the literature are very limited and much more research is needed in this area. This study focuses on establishing a broad theoretical framework regarding contextual marketing. In addition, the study aims to assist business managers in making relevant decisions by examining up-to-date statistics and contextual marketing strategies on the subject.
\end{abstract}

Keywords: Context, Targeting, Contextual Marketing, Contextual Advertising

\section{GiRiş}

Günümüzde pazarlama sadece marka veya ürüne değil, müşteriye ve müşteri intiyaçlarına odaklanmaktadır. İşletmelerin sundukları teklifin ne kadar iyi olduğu hedef pazarlarına sundukları değerle orantılıdır. Teknoloji geliştikçe, tüketicilerin bekleme tahammülü azalmakta, dikkat süreleri kısalmakta ve talepleri artmaktadır. Dolayısıyla pazarlamacıların, tüketicilerin dikkatini çekmek ve elde tutmak için bağlamsal ve kişiselleştirilmiş stratejilere ihtiyaçları vardır (Rivard, 2017).
Bağlama dayalı hedefleme, bir işletmenin, kullanıcıların konumu, zamanı, davranışı gibi faktörlere dayalı kapsamlı bir hedefleme stratejileri setine atıfta bulunmaktadır. Mobil çağda hassas hedeflemenin ideali, doğru bilginin doğru kişiye, doğru yerde ve zamanda ulaştırılmasıdır. Bu hedefe ulaşıldığında, ticari bilginin durumsal alaka düzeyinin bir kullanıcı için yüksek olduğu kabul edilir. Pazarlama literatüründe bu, içeriğin yanı sıra bağlamın önemini vurgulayan bağlamsal pazarlama olarak bilinmektedir (Lian, Cha \& Xu, 2019: 30).

Bağlamsal pazarlama, bir reklamı o sayfanın içeriğine bağlı

\footnotetext{
* In this article, the principles of scientific research and publication ethics were followed. / Bu makalede bilimsel araştırma ve yayın etiği ilkelerine uyulmuştur.

\section{${ }^{1}$ Yasemin GEDiK}

ORCID ID: 0000-0002-1166-3227

Dr., Beykent Üniversitesi, Sosyal Bilimler Enstitüsü, İşletme Yönetimi Ana Bilim Dalı, İstanbul, Türkiye, dr.yasemingedik@hotmail.com

Dr., Beykent University, Institute of Social Sciences, Business Administration, Istanbul, Türkiye, dr.yasemingedik@hotmail.com

Geliş Tarihi/Received

Kabul Tarihi/Accepted

Çevrimiçi Yayın/Published

: 20.05.2021

: 22.12.2021

: 24.12.2021
}

Makale Atıf Önerisi /Citation (APA):

Gedik, Y. (2021). Bağlamsal Pazarlama: Avantajları, Zorlukları ve Stratejileri Üzerine Kavramsal Bir Değerlendirme. İmir Sosyal Bilimler Dergisi, 3 (2), 175-186. DOI :10.47899/ijss.20213207 
olarak bir web sitesi sayfasıyla eşleştirir. Odak noktası, içeriği kimin tükettiği değil, tüketilen içeriktir. Geleneksel bağlama dayalı hedefleme, sayfadaki anahtar kelimeleri hedeflenmek istenilen anahtar kelimelerle eşleştirerek yapılır. Ayrıca kategori düzeyinde de çalışabilir. Örneğin, bir bisiklet markası, reklamını bisikletler, bisiklet incelemesi, bisiklet bakımı, bisiklet gezileri gibi konulara odaklanan herhangi bir sayfada göstermek isteyebilir veya gözlük markası, reklamının kitaplarla ilgili bir sayfada yayınlanmasını seçebilir (https://www.criteo.com/, 2020). Bağlamsal pazarlamanın geçmişi Rayport ve Sviokla (1994) tarafından pazar alanı işlemi olarak adlandırılan teoriye dayanmaktadır (Luo, 2003: 232). Yazarlar, Aucnet sisteminin, envanterin fiziksel konumunu ve gerçek alımsatım sitesini bağımsız hale getirdiğini, fiziksel satıcı ile fiziksel alıcı arasındaki geleneksel pazar etkileşimi ortadan kaldırdığını öne sürmektedir. İşlemin içeriği (arabalarla ilgili bilgiler arabaların yerini alır); gerçekleştiği bağlam (elektronik ekran yüz yüze bir müzayedenin yerini alır) ve gerçekleşmesini sağlayan altyapı (bilgisayarlar ve iletişim hatları) farklıdır. Bu pazar alanı işlemi, daha düşük maliyetlere izin verir, kolaylık ve her an her yerde bulunma özelliği sunar (Rayport \& Sviokla, 1994).

COVID-19 krizinin ortasında, 2020 yılında 145.1 milyar \$ olarak tahmin edilen küresel bağlamsal reklamcılık pazarının, \%17.5'lik yıllık bileşik büyüme oranıyla (CAGR), 2027 'de 447.9 milyar \$ revize edilmiş bir büyüklüğe ulaşacağı tahmin edilmektedir (https://www.reportlinker.com/, 2021). Bağlamsal reklam harcamalarındaki büyüme, reklamların ekrandaki içerikleriyle alakalı olmasına odaklanılmasıyla devam edecektir. Reklamların ekrandaki içerikle alakalı olmasını sağlamak, tüketici için daha sorunsuz bir deneyim yaratacak ve nihayetinde etkileşimi artıracaktır (Broughton, 2019). Öte yandan, pazarın büyümesini yönlendiren ana faktörler arasında artan sosyal medya kullanıcısı sayısı, kişiselleştirilmiş pazarlama stratejileri ve artan mobil reklam trendi sayılabilmektedir (https://www.marketsandmarkets.com/, 2018).

Wojdynski ve Bang (2016), reklamlar, mevcut içerikle alakalı olduğunda, reklamlara görsel ilginin daha fazla olacağını bulmuştur. Chun, Song, Hollenbeck \& Lee (2014), çevrimiçi bağlamsal reklamın marka tanınırlığını artırdığını ve reklama karşı olumlu tavırlar uyandırdığını ortaya çıkarmıştır. Shukla (2009), bağlamsal faktörlerin satın alma kararları üzerinde en güçlü etkiye sahip olduğunu ve marka sadakatini etkilediğini göstermiştir. Lee ve Jun (2007), pazarlama teklifinin bağlamsal algılanan değerinin (CPV, contextual perceived value), yeniden satın alma niyeti, müşteri memnuniyeti ve algılanan kullanışlılık üzerinde önemli bir etkiye sahip olduğunu tespit etmiştir. Luo ve Seyedian (2003) çalışmasına göre, müşterilere kişiselleştirilmiş, gerçek zamanlı bilgi sağlamaya yönelik bağlamsal pazarlama yaklaşımı, e-ticarette rekabet avantajı sağlayacaktır. (Luo, 2003), daha yüksek düzeyde bağlamsal pazarlamanın, daha yüksek düzeyde algılanan web sitesi değeri, daha yüksek düzeyde algılanan kullanıcı memnuniyeti ve daha fazla çevrimiçi satın alma ile ilişkili olduğunu tespit etmiştir.

Ping (2019: 1), bağlamsal pazarlamanın, işletmeler tarafından hızla benimsendiğinin ancak ilgili teorik çalışmaların hala başlangıç aşamasında olduğunun altını çizmektedir. Bununla birlikte, bağlamsal pazarlama literatüründe yapılan deneysel ve kuramsal çalışmalar oldukça kısıtlıdır ve çok daha fazla gelişmeye ihtiyaç duymaktadır. Bu çalışma, bağlamsal pazarlama ilgili geniş bir teorik çerçeve oluşturmaya odaklanmaktadır. Ayrıca çalışma, konuyla ilgili güncel istatistikler ve bağlamsal pazarlama stratejilerini de inceleyerek ilgili kararları alırken işletme yöneticilerine yardımcı olmayı amaçlamaktadır. Bu amaçla öncelikle bağlam ve hedefleme kavramları incelenmiş, ardından bağlamsal reklamcılık (bağlamsal hedefleme) ve bağlamsal pazarlama kavramları açıklandıktan sonra çalışma, bağlamsal pazarlamanın avantajları, bağlamsal pazarlamada karşılaşılan zorluklar ve bağlamsal pazarlama stratejileri anlatılarak sonlandırılmıştır.

\section{BAĞLAM KAVRAMI}

Bağlam terimi farklı bilimsel disiplinlerde farklı anlamlarda kullanılmaktadır. Dilbilim ve edebiyat bilimlerinde bağlam, belirli koşullar altında yaratılan sözlü ifadelerin veya metinlerin analiz edilmesini ve anlaşılmasını ifade eder. Psikoloji ve sosyolojide bağlam, insan davranışı ve sosyal ağ ilişkilerinin şekillenmesi üzerinde etkili bir faktör olarak kabul edilir (Zerr, Albert ve Forster, 2017:3). Bilgisayar biliminde bağlam, bağlam duyarlı yardım, bağlamsal arama, çoklu görev bağlam değiştirme, psikolojik bağlamsal algı gibi farklı alanlarında birçok şekilde kullanılmıştır (Chen \& Kotz, 2000:2). Conti, Nguyen ve Crispo (2010: 6) bağlamı, bazı değişkenlerin durumu (örn. konum, zaman, sıcaklık, gürültü ve ışık), diğer cihazların varlığı, kullanıcı ile akıllı telefon arasındaki belirli bir etkileşim veya bunların bir kombinasyonu şeklinde tanımlamaktadır.

Lopez (2016) kitabında, pek çok kişinin, bağlamın mobil internetteki konum bilgilerinden başka bir şey olmadığını düşündüğünü ancak bağlamın aslında cihazların türünü, davranış durumunu, hava koşullarını, çevresel koşulları, sosyal rolleri ve ilişkileri, zamanı, hareket durumunu ve mevcut işlem durumunu içerdiğini iddia etmektedir (Zheng, 
Lin \& Cai, 2021:82). Dey (2001:5) bağlamı, bir varlığın durumunu karakterize etmek için kullanılabilecek herhangi bir bilgi olarak tanımlamaktadır. Bir varlık, kullanıcı ve uygulamaların kendisi de dâhil olmak üzere, bir kullanıcı ile uygulama arasındaki etkileşimle ilgili olduğu düşünülen bir kişi, yer veya nesnedir. Bağlam, yalnızca sabit bir etkileşim kaynakları kümesine sahip önceden tanımlanmış bir ortamın durumu değildir. Yeniden yapılandırılabilir, taşınabilir, dağıtılmış ve çok ölçekli kaynaklardan oluşan sürekli değişen bir ortamla etkileşim sürecinin bir parçasıdır. Bağlam, gelişmekte olan bilgi toplumu için sosyal içermeyi etkileyecek yeni hizmetlerin geliştirilmesinde anahtardır (Coutaz, Crowley, Dobson \& Garlan, 2005:49-53).

Schilit et al. (1994) bağlamı, bilgi işlem bağlamı (ağ bağlantısı, iletişim maliyetleri vb.); kullanıcı bağlamı (kullanıcı profili, konum vb.) ve fiziksel bağlam (aydınlatma, gürültü vb.) olmak üzere üç kategoride incelemişlerdir. Chen ve Kotz (2000), zaman bağlamını (günün saati, hafta, ay ve yılın mevsimi) dördüncü bir bağlam kategorisi olarak eklemişlerdir. Figge (2004), mobil ticaret uygulamalarını kullanıcının bir hizmete eriştiği mekânsal, kişisel ve zamansal bağlama göre uyarlamak için yeni bir kavram olarak durum bağımlılığını tanıtmıştır. Figge (2004) durum bağımlılığını, kullanıcı kimliği (kişisel profil, arka plan, tercihler vb.), erişim konumu ve erişim süresi ile üç boyutlu bir alan olarak açıklamaktadır (akt. Lee \& Jun, 2007: 801). Öte yandan, Zerr et al. (2017: 5), bağlam faktörlerini iki boyutlu bir matris olarak (Tablo 1) sınıflandırmaktadırlar.

Tablo 1: İki boyutlu bağlam sınıflandırması ve bağlam faktörleri örnekleri

\begin{tabular}{|c|c|c|}
\hline $\begin{array}{l}\text { Bağlam } \\
\text { faktörleri }\end{array}$ & Gizli (statik) & Akut (dinamik) \\
\hline $\begin{array}{ll}\text { İçsel (Kişi } & \text { ile } \\
\text { ilgilidir } & \text { ve } \\
\text { sağlayıcıdan } & \\
\text { gerçek zamanlı } \\
\text { veya daha uzun } \\
\text { vadede } \\
\text { etkilenebilir) } \\
\end{array}$ & $\begin{array}{l}\text { Çevre, kişilik tipi, } \\
\text { demografik } \\
\text { özellikler, kültürel } \\
\text { etki, etkileşim } \\
\text { geçmişi vb. }\end{array}$ & $\begin{array}{l}\text { Duygusal durum, } \\
\text { eylem nedeni } \\
\text { /niyet, etkileşim } \\
\text { davranışı vb. }\end{array}$ \\
\hline $\begin{array}{l}\text { Dışsal (Kullanım } \\
\text { durumuyla } \\
\text { ilgilidir ve } \\
\text { sağlayıcı } \\
\text { tarafından bir } \\
\text { çerçeve olarak } \\
\text { değerlendirilir) }\end{array}$ & $\begin{array}{l}\text { İklim durumu, } \\
\text { mevsimler, } \\
\text { ikamet yeri, } \\
\text { sosyal ağ vb. }\end{array}$ & $\begin{array}{lr}\text { Kültürel } & \text { çevre, } \\
\text { sosyal çevre / } \\
\text { insanlar, } & \text { mevcut } \\
\text { etkileşim r yeri } \\
\text { hava, rıcaklık, } \\
\text { zaman, kullanılan } \\
\text { ortam vb. }\end{array}$ \\
\hline
\end{tabular}

Kaynak: Zerr et al., 2017: 5

\section{HEDEFLEME KAVRAMI}

Hedefleme sözlük anlamıyla, herhangi birine reklam, eleştiri veya bir ürünü yönlendirmek olarak tanımlanabilir (https://dictionary.cambridge.org/, 2021). Müşterileri hedefleyen milyarlarca reklam olduğundan, mevcut reklamcılık eğilimi, bir grup alakalı müşteriyi hedeflemek ve reklam stratejilerini ilgi alanlarına göre özelleştirmektir. Genel olarak, hedefleme yöntemleri belirli bir bağlamdaki kullanıcıları uygun bir reklamla eşleştirir. Kullanıcının bağlamı, kullanıcının o anda ziyaret ettiği sayfadan, saatten ve kullanııının geçmiş çevrimiçi davranışından oluşur. Kullanımdaki en popüler hedefleme teknikleri, davranışsal hedefleme ve bağlamsal hedeflemedir. Bağlamsal hedefleme, popüler bir anahtar kelime hedefleme biçimidir. Davranışsal hedefleme, müşterileri hedeflemek için bir ölçü olarak kullanıcının göz atma davranışını kullanırken bağlamsal hedefleme, reklamları sunmak için web sayfasının içeriğini dikkate alır ( Radhika, Thottungal \& Nizar, 2016: 1; Pandey et al., 2011:1805). Bağlamsal hedefleme, bir sonraki bölümde detaylı olarak anlatılacaktır.

Davranışsal hedefleme, ziyaret edilen siteler ve belirli içerik türlerine ilgi duyan siteler dâhil olmak üzere çevrimiçi davranış hakkındaki bilgileri kullanarak, belirli tüketici gruplarının daha ilginç bulacağı reklamlar sunmaya çalışır. Reklamlar tüketicinin ilgi alanlarıyla daha iyi eşleşirse, tüketicilerin mesaja yanıt verme olasılığı daha yüksektir ve reklam verenler bu tür bir kitleye sunulan reklamlar için daha fazla ödeme yapmaya istekli olacaktır. Davranışsal hedeflemeyi kullanan işletmeler, standart ağ reklamcılığından daha başarılıdır (Beales, 2010: 1). Davranışsal hedefleme, çevrimiçi reklam verenler tarafından kampanyalarının etkinliğini artırmak için kullanılan bir tekniktir ve çevrimiçi reklamcılık pazarında giderek daha önemli bir rol oynamaktadır. Yan, Liu, Wang, Zhang, Jiang ve Chen (2009:1), aynı reklamı tıklayan kullanıcıların Web'de benzer davranışlara sahip olacaklarını ve bir reklamın tıklama oranının (TO), sponsorlu bir aramada davranışsal hedefli reklamcılık için kullanıcıları uygun şekilde bölümlere ayırarak ortalama \%670'e kadar arttırılabileceğini tespit etmişlerdir.

Davranışsal hedeflemenin arkasındaki anahtar, reklam verenlerin reklamları yalnızca yüksek değere sahip belirli bir demografideki (araba satın alma olasılığı yüksek olan kişiler gibi) kullanıcılara göstermesi ve bunu kullanıcı başına daha fazla sayıda fırsatla (reklam gösterilecek yerler) 
birleştirebilmesidir. Dahası, bir kullanıcı hakkında daha fazla bilgi topladıkça, onlara gelecekteki her etkileşimde daha iyi bir deneyim sağlamak mümkündür Pandey, Aly, Bagherjeiran, Hatch, Ciccolo, Ratnaparkhi \& Zinkevich, 2011: 1805). Diğer taraftan, tüketiciler hedeflenen bir reklamın kendileri hakkında neye işaret ettiğine tepki verebilmektedirler. Örneğin, çevre dostu bir ürün için hedeflenmiş bir reklamı görüntüledikten sonra tüketici, reklam verenin kendisini çevre dostu biri olarak gördüğüne inanabilir (yani, hedeflenen reklam, zımni bir sosyal etiket görevi görebilir). Daha sonra çevre dostu olmakla ilgili algılarını ve bunun sonucunda da çevre dostu ürünlere yönelik davranışını değiştirebilir ( Samat, Acquisti \& Babcock, 2017: 300). Bununla birlikte literatürde yaygın olarak kullanılan diğer hedefleme türleri aşağıdaki gibi sıralanabilmektedir (Clevinger, 2021; Hemdev, 2019):

- Demografik hedefleme: Bu hedefler yaş, cinsiyet, etnik köken, ırk, gelir, eğitim, din, ekonomik durum ve daha fazlasına dayanır.

- Coğrafi hedefleme: Bu hedefleme, belirli bir yeri temel alır ve bir ülke veya bölge kadar geniş veya bir şehir veya mahalle kadar spesifik olabilir.

- Yeniden hedefleme: Bir marka veya ürün teklifine daha önce ilgi gösteren izleyicilere reklamın gösterilmesidir.

- IP Hedefleme: Bir internet protokolü (IP) adresiyle ilişkili adres kullanılarak belirlenen fiziksel konumuna göre mobil veya masaüstü cihaza dijital reklamlar sunulmasıdır. GumGum tarafından hazırlanan 116 üst düzey yöneticinin katıldığı Contextual Advertising: The New Frontier Report'a göre, bağlamsal hedefleme, $A B D$ 'de en yaygın kullanılan hedefleme türü (\%49) olmuştur. Bağlamsal hedeflemeyi, \%46 ile demografik, $\% 44$ ile coğrafi konum ve $\% 25$ ile davranışsal hedefleme takip etmiştir (https://insights.gumgum.com/ ,2018).

\section{BAĞLAMSAL HEDEFLEME (BAĞLAMSAL REKLAMCILIK)}

Bağlamsal reklamcılık, kâr amacı gütmeyen işlemsel olmayan web sitelerinin (yani doğrudan hiçbir şey satmayan siteler) gelirlerinin büyük bir kısmını oluşturmaktadır (Niu, Ma \& Zhang, 2009: 505). İçerik eşleşmesi olarak da tanımlanan bağlamsal reklamcılık, mobil tarayıcılarda görüntülenen içerik gibi web sitelerinde veya diğer medyada bulunan reklamlar için hedeflenen bir reklam biçimidir. Web sayfaları genellikle çok sayıda metin içerdiğinden, web sayfalarından bazı temsili anahtar kelimeler çıkarmak veya oluşturmak çok yararlıdır. Reklamlar, kullanıcıya gösterilen içeriğe göre otomatik sistemler tarafından seçilir ve sunulur. Web sayfasının temel fikrini yakalayabilecek bir anahtar kelime kümesi seçmek, bağlamsal reklamcılık algoritmalarında çok önemli bir görevdir. Tipik anahtar kelime çıkarma algoritmaları dört adımdan oluşur (Armano, Giuliani \& Vargiu, 2011: 1; Liu, Azimi \& Zhang, 2014: 345):

- İçerik çıkarma: Bir HTML sayfasının ana içeriğinin çıkarılması

- Aday anahtar kelime seçimi: İçerikten bir aday anahtar kelime kümesi dönüştürülmesi

- Özellik Çıkarma: Aday anahtar kelimeleri bazı kurallar kullanarak bir dizi özelliğe dönüştürme

- Tahmine Dayalı Model: Aday anahtar kelimeleri çıkarılan özelliklere göre alakalı ve alakasız anahtar kelimeler olarak sınıflandırılması

Bağlamsal hedefleme, belirli bir süre boyunca o kullanıcı hakkında toplanan, depolanan ve analiz edilen verileri kullanmak yerine, bir kullanıcının niyetlerini ve ilgi alanlarını tespit etmek için oturum bilgilerini kullanır. Günümüzde kullanıcı verilerinin toplanmasının sınırlanması için tüketicilerde oluşan farkındalık, kamu ve düzenleyici baskıları da arttırmaktadır. Kişisel verilerin daha katı kullanımını ve gizliliğin korunmasını zorunlu kılan Genel Veri Koruma Yönetmeliği (GDPR) ve California Tüketici Gizliliği Yasası (CCPA) düzenlemeleriyle, bağlamsal hedeflemeye yönelik talep artmaktadır (https://www.knorex.com/, 2021). Bununla birlikte, bağlamsal reklamlar için temel başarı faktörlerinden biri, çevreleyen içerikle alaka düzeyidir. Bağlamsal reklamcılığının temeli, sayfadan kelime öbekleri çıkarmak ve bunları reklamların teklif cümlesiyle eşleştirmektir. Ancak, tek tek kelime öbekleri ve kelimelerin birden çok anlamı olabilir ve / veya yanlış eşleşen reklamlara yol açan sayfanın genel konusuyla alakasız olabilir Broder, Fontoura, Josifovski \& Riedel, 2007: 566). Diğer taraftan, bağlamsal reklamcılıkta kullanılan üç önemli ücretlendirme modeli bulunmaktadır (Niu et al., 2009: 506):

- Gösterim başına maliyet (CPM, cost-per-impression): CPM modelinde, reklam verenler reklamlarının gösterimi için ödeme yapar. CPC, geleneksel medyada (örn. dergi ve televizyon) veya afiş reklamlarında yaygın olarak kullanılır ve reklam verenin amacı marka bilinirliğini artırmak olduğunda daha uygundur.

- Tıklama başına maliyet (CPC, cost-per-click): CPC modelinde, reklam verenler yalnızca bir kullanıcı 
reklamlarını tıkladığında ödeme yapar. Son birkaç yılda, Google ve Yahoo gibi şirketlerde sponsorlu aramanın büyümesiyle birlikte, CPC ücretlendirme modeline doğru büyük bir geçiş olmuştur Bunun temel nedeni, CPC modelinin bir reklamın hedef kitlesinde olmayan tüketicilere reklam verme riskini azaltmasıdır.

- İşlem başına maliyet (CPA, cost-per-action): CPA modelinde, reklamverenler yalnızca bir kullanıcı belirli bir eylemde bulunduğunda (ör. Bir form doldurduğunda) veya bir işlemi tamamladığında ödeme yapar. Son zamanlarda Google, eBay, Amazon ve Snap.com gibi birçok şirket bu şekilde reklam satmaya başlamıştır. CPA tıklama sahtekârlığını ortadan kaldırır.

Bağlamsal reklamcılık genellikle doğrudan pazarlama kategorisine girer yani amacı bir kampanyanın etkisinin kullanıcının tepkisiyle ölçüldüğü doğrudan yanıt olan reklamdır. Genel olarak çevrimiçi reklamcılığın ve özellikle bağlamsal reklamcılığın avantajlarından biri, geleneksel medyaya kıyasla, kullanıcı tepkisini ölçmenin nispeten kolay olmasıdır. Genellikle istenen anında tepki, kullanıcının reklamdaki bağlantıyı takip etmesi ve reklam verenin web sitesini ziyaret etmesidir. Gelir, yayıncı ve ağ arasında paylaşılır (Broder et al., 2007: 560). İlk büyük bağlamsal reklamcılık platformu, Google tarafından 2003 yılında kurulmuştur. Günümüzde, tüm büyük arama motorları (Yahoo, Microsoft Live Search vb.), reklam yayıncıları ve Web sitesi sahipleri için benzer hizmetler sunmaktadır. Bağlamsal bir reklamcılık ağı dört aktörden oluşmaktadır (Pak \& Chung, 2010: 252):

- Reklam veren: Genellikle ürünlerini veya hizmetlerini tanıtan, ağa reklam sağlayan ve sonuç için ödeme yapan bir şirkettir.

- Yayıncı: Sayfalarına bağlamsal reklam blokları yerleştiren ve reklam gösterimleri veya tıklamaları için ödeme alan bir Web sitesinin sahibidir.

- Reklam platformu: Reklamları seçen, bunları bir yayıncının Web sayfasına yerleştiren ve geliri yayıncı ile paylaşan ana sistemdir.

- Kullanıcı: Web sayfalarını ziyaret eden ve reklamlarla etkileşime giren kişidir.

Bağlamsal hedefleme olarak da bilinen bağlamsal reklamcılık, hedeflenen ve otomatikleştirilmiş bir dijital reklamcılık biçimini tanımlar. Bağlama dayalı reklamlar, arama motorları, sosyal medya, haber siteleri ve mobil cihazlar aracılı̆ı̆yla iletilebilir. Bununla birlikte, yüksek hedeflemeli bağlama dayalı reklamcılık sunan ilk platformlardan biri olan Google'ın Adwords ve Adsense araçları bunu sağlamanın en popüler yollarından biridir. Tüketiciler, giderek daha fazla kişiselleştirilmiş deneyim talep ettiklerinden bağlama dayalı reklamlar ilgilerini çekmektedir (Berry, 2019; Kakkar, 2017; https://www.marketing-schools.org/, 2021). Öte yandan, bağlamsal reklamcılıktaki en heyecan verici gelişmelerden biri, teknoloji yeteneklerinin bir sayfadaki (veya ekrandaki) kelimelerin ötesinde ses, video, resim ve daha fazlasına genişletilmesidir. Makine öğrenimi ve yapay zeka, günümüzün önde gelen bağlamsal zeka çözümlerini güçlendirerek onları daha akıllı, daha uygulanabilir, markaya daha uygun ve daha ölçülebilir hale getirmektedir. Bu, bağlamın geleceğinin parlak olduğunu ve pazarlamacılar için bağlamın uygulanmasını daha fazla kanala genişletme ve başarı fırsatları açtığını göstermektedir (Wise, 2019).

\section{BAĞLAMSAL PAZARLAMA KAVRAMI}

Teknoloji, tüketici davranışını temelden değiştirmekte ve endüstrilerin çalışma şeklini dönüştürmektedir. Günümüzde fiziksel ve dijital dünyalar arasındaki sınırları tanımlamak giderek zorlaşmaktadır. Tüketiciler artık tamamen çevrimiçi veya çevrimdışı alışveriş yapmamakta, bunun yerine ihtiyaçlarına en uygun kanalı kullanarak karma bir yaklaşım sergilemektedir (Vanessa \& Japutra, 2017: 56). Bağlamsal pazarlama, tüketicilere gerçek zamanlı olarak ihtiyaç duydukları anda ve alakalı bilgileri sunmayı içerir. Bir banner reklam, müşterinin aradığı bilgiyle alakalı değilse başarılı olmayacaktır. Örneğin, Ulusal Futbol Ligi sonuçlarını arayan bir kişi, hayat sigortası çevrim içi tanıtımını alakasız ve bağlam dışı bulacak ve memnuniyet veya satın alma niyeti / kararı oluşturma olasılığı düşecektir (Luo \& Seyedian, 2003: 96). Fan ve Chang (2009: 1803), güçlü alaka düzeyinin tıklanma sayısını arttıracağını vurgulamaktadırlar.

Bağlamsal pazarlama, tüketicilerin internette gezinirken kullandıkları arama terimleri gibi kullanıcı bilgilerine dayalı hedefli reklamcılık sağlayan çevrimiçi ve mobil bir pazarlama yöntemidir. Amaç, müşterilere hâlihazırda ilgi gösterdikleri ürün ve hizmetleri temsil eden reklamlar sunmaktır. Örneğin, bir müşteri yakıt açısından verimli olduğu bilinen otomobiller için internette arama yaptıktan sonra, günlük haber sitelerini gezdiğinde okuduğu haberlerin yanında görünen reklamlar tamamen hibrit otomobillerle ilgili olabilir. Zaten yakıt tasarrufu yapmayı düşünen müşteri, hibrit otomobilleri kontrol etmek için reklama tıklayacaktır (Jain, 2021). Öte yandan, bağlamsal pazarlama, anlamı hala gelişmekte olan bir terimdir. Bağlamsal pazarlama, hedeflenmiş veya içerik eşlemeli reklamcılık gibi belirli tekniklerle ilişkilendirir, ancak en geniş anlamıyla, pazarlamanın etkinliğini artırmak için mevcut müşteri bilgileriyle birlikte bir bireyin bağlamı hakkındaki bilgileri (nerede oldukları veya belirli bir zamanda ne yaptıkları gibi) kullanmak anlamına gelir. Bağlamsal pazarlama, kitlesel 
pazarlamadan segmentasyona, kişiselleştirmeye ve nihayet bağlamsal olmaya doğru ilerlemede bir sonraki adımdır. Bu nedenle, genellikle daha önceki diğer yaklaşımlarla birlikte kullanılabilmektedir (The Economist, 2015: 3).

Bağlamsal pazarlama, mobil internet ve bağlamsal teknolojilerin desteğiyle bağlamsal bilgi analizine dayalı olarak tüketicilerle iletişim kurmak temeline dayanır. Amaç, tüketicileri bağlama duyarlı hale getirmek ve tüketim davranışına rehberlik etmektir. Giderek daha fazla işletme, bağlamsal pazarlamanın avantajını fark etmekte ve bunu iş modellerine taşımaktadır. Geleneksel pazarlamayla karşılaştırıldığında, bağlamsal pazarlama, operasyon alanı-zaman boyutu, pazarlama işlevi ve değer yaratma açısından birçok avantaja sahiptir (Ping, 2019: 1). Bağlamsal pazarlama, doğru kişilere cihazlarında en yararlı bilgileri doğru zamanda sağlamaktadır. Geleneksel pazarlama modeli, önce ürünleri, daha sonra hedef tüketicileri seçerken, bağlamsal pazarlama, ürünleri belirli tüketiciler için özelleştirmektedir (Zheng et al., 2021: 82). Bağlamsal pazarlama, sahte haberlerin yayılmasını önleyerek reklamların yalnızca sundukları ile alakalı içeriğin yanında gösterilmesini sağlar. Belirli kullanıcıları hedeflemediği için, hiçbir şekilde GDPR, CCPA, IDFA gibi üçüncü taraf tanımlama bilgilerine güvenmez. Bununla birlikte, alakalı içeriği belirlemek eskiden basit bir anahtar kelime eşlemesiyle gerçekleşirken reklam teknolojisinin geri kalanı gibi, bağlamsal hedefleme de yapay zekâdaki (AI) gelişmeler sayesinde muazzam bir şekilde büyümüştür. Günümüzde doğal dil işleme (NLP), her sayfanın bağlamının ve duyarlılığının daha derin bir şekilde anlaşılmasına olanak tanır (https://www.criteo.com/ , 2020).

Bağlamsal pazarlama, kullandıkları arama terimleri veya en son web tarama etkinliği gibi kullanıcı bilgilerine dayalı olarak hedeflenmiş reklamcılık sağlayan çevrimiçi ve mobil pazarlamayı ifade eder (https://www.marketingschools.org/ , 2021). Örneğin, sevdiği futbol kulübüyle ilgili en son haberler için bir spor sitesine göz atan bir kullanıcı, birdenbire satın alabileceği kulüp ürünlerini gösteren açılır bir reklam penceresi ile karşılaşabilir ya da Avrupa tatili arayan bir başka kullanıcı, Fransa'ya en ucuz uçak biletlerini sunan reklamları görmeye başlayabilir. Bağlamsal pazarlama, doğru mesajı, doğru zamanda, doğru kişiye pazarlamaktır (Kakkar, 2017). Tüketiciler, kendilerine yönelik pazarlama materyallerinin yararlı ve kendi durumlarıyla son derece alakalı olmasını istemektedir. Beklentiler, kendilerine en değerli içeriği sağlayan markaları seçme ve onlarla en kişiselleştirilmiş şekilde iletişim kurma eğilimindedir. Bağlamsal pazarlamanın kritik olduğu yer burasıdır (Rivard, 2017). Adlucent 2016 araştırmasına göre, müşterilerin \% 71'i ilgi alanlarına ve alışveriş alışkanlıklarına göre uyarlanmış reklamları tercih etmektedir. Ayrıca, kişiselleştirilmiş reklamlar etkileşimi de arttırmaktadır. Araştırmadan elde edilen ilginç bir sonuç, müşterilerin bilinmeyen bir markayı içeren bir reklamı, reklam tercihlerine göre uyarlanmışsa neredeyse iki kat daha fazla tıklama olasılığı bulunmasıdır (Kirkpatrick, 2016). Econsultancy ve Google'nın, Mart 2017 'de 514 yöneticiyle gerçekleştirdiği ankette, katılımcıların \% 90'ı, kişiselleştirmenin işletmenin karlıığına önemli ölçüde katkıda bulunduğunu iletmiştir (https://www.thinkwithgoogle.com/, 2017).

Epsilon'un 18-64 yaş arası 1.000 tüketicinin katıldığı 2017 çevrimiçi anketine göre, katılımcıların \% 80'inin, kişiselleştirilmiş deneyimler sunan bir kuruluşla iş yapma olasılıklarının daha yüksektir ve \% 90'ı kişiselleştirmeyi çekici bulmaktadır. Kişiselleştirilmiş deneyimlerin çok çekici olduğuna inanan katılımcıların, bir markanın en değerli müşterisi olma olasılıkları 10 kat daha yüksektir (https://www.epsilon.com/ , 2018). Benzer şekilde Segment'in 18 yaş ve üzeri toplam 1.006 kişiyle gerçekleştirdiği 2017 State of Personalization Report, tüketicilerin ortalama \% 71'inin, alışveriş deneyimleri kişisel olmadığında hayal kırıklığı yaşadığını vurgulamaktadır. Ankete katılan müşterilerin \% 49'u, bir markadan kişiselleştirilmiş bir öneri aldıktan sonra başlangıçta satın almayı düşünmedikleri bir ürünü satın almıştır. Tüketicilerin \% 44'ü, bir işletmeyle yaşadığı kişiselleştirilmiş bir alışveriş deneyiminden sonra muhtemelen tekrar ürün satın alacağını belirtmiştir (http://grow.segment.com/, 2017).

Bağlamsal pazarlama, müşterilerin kim olduğunu, nerede bulunduklarını ve ne yaptıklarını bulmaya çalışır. İşletmenin bakış açısından bağlamsal pazarlama aktif ve dinamiktir. Ancak müşterinin bakış açısından pasif ve reaktif olabilir. Müşteri, belirli bir zamanda ve yerde sunulan bilgileri pasif olarak alır ve yanıtlar ya da görmezden gelir. Müşterilere doğru zamanda bağlamsal bilgi sağlamak, gerçek zamanlı pazarlama teorisiyle uyumludur. Gerçek zamanlı pazarlama, işletmenin, müşterinin tercihlerine ve eylemlerine bağlı olarak, müşterinin bulunduğu yerde gerçek zamanlı olarak ürün ve hizmetler sunma derecesini ifade eder

(Luo \& Seyedian, 2003: 97). Mobil teknoloji, akıllı telefon kullanıcıları genellikle GPS koordinatlarının cihazlarından alınmasına izin verdiğinden, işletmelerin müşterilerin fiziksel konumunu algılamasını da sağlamaktadır. Bağlamsal pazarlamanın diğer örnekleri arasında konuma dayalı teklifler ve hizmetler bulunmaktadır. İsviçre'nin ulusal demiryolu operatörü olan İsviçre Federal Demiryolları, 
yolculara seyahat deneyimlerini iyileştirmek için konumlarını kullanan mobil uygulamalar sunmaktadır. Uygulama, yolcuların tren değiştirmek için bir istasyonda beklediklerini algılamakta ve onlara yakındaki mağaza ve restoranlarda indirimler sağlamaktadır (The Economist, 2015: 6).

\section{BAĞLAMSAL PAZARLAMANIN AVANTAJLARI}

Ziyaretçilere ilgileneceği reklamlar veya web sitelerinin sunulması, reklam başına tıklama sayısını arttırmaya, satış olasılıklarının gerçek satışlara dönüşmesini sağlamaya ve geleneksel reklamların tüketicileri kesintiye uğratan doğasını yok etmeye yardımcı olmaktadır (https://www.marketing-schools.org/, 2021). Bağlamsal pazarlama, bir bireyin durumuna ve intiyaçlarına göre kişiselleştirilmiş veriye dayalı içerik sağlayarak genel müşteri deneyimini geliştirir. Hedef kitlenin kullandığı platform aracılığıyla sunulan ilgi çekici içerik, daha iyi müşteri ilişkileri geliştirmeye yardımcı olur (Rivard, 2017). Adobe ve Microsoft (2018) araştırmasına göre, tüketicilerin \% 94'ü arzuladıkları türden kişiselleştirilmiş marka deneyimi beklentilerini karşılayamama nedeniyle bir marka ile iliş̧ilerini kesmeyi düşünmektedir. Luo (2003: 232), bağlamsal pazarlamanın işletmelere, sadık müşteriler, çapraz ve ek satış fırsatları sağladığını vurgulamaktadır. Bağlamsal pazarlama ayrıca müşterilerin tekrar satın alma olasılıklarını da yükseltmektedir.

Bağlamsal pazarlamayı başarılı bir şekilde kullanan işletmeler, pazar segmentlerinin daha verimli hedeflenmesi ve daha değerli bir ürünü daha yüksek bir fiyata sunmak gibi önemli rekabet avantajları elde edebilmektedir (Luo ve Seyedian, 2003: 97). Dahası, bağlamsal pazarlamayı uygulamak, büyük bir yatırım gerektirmez. Bağlamsal pazarlama, marka farkındalığını, hatırlamayı ve katılımı teşvik etmek için işletmelerin markalarını en uygun zamanlarda öne çıkarmalarına ve merkeze yerleştirmelerine de olanak tanır. Müşteriler, bağlamsal pazarlama ile teklifi bir reklam olarak görmekten daha çok problemlerine bir çözüm olarak düşünebileceğinden, bağlamsal pazarlama müşterileri kesintiye uğratmaz (Rivard, 2017).

Bağlamsal reklamcılık, günümüz Web'inin önemli bir parçasıdır. Tüm taraflara fayda sağlar: Web sitesi sahipleri ve bir reklam platformu geliri paylaşır; reklam verenler yeni müşteriler elde eder ve web sitesi ziyaretçileri yararı referans bağlantılarına sahip olur. Bir web ayfası için seçilen reklamların alaka düzeyi, tüm sistemin çalışması için çok önemlidir (Pak ve Chung, 2010: 251). Öte yandan, bağlam, anahtardır; iletişim kurma veya bozma gücüne sahiptir. Bağlam, göz ardı edildiğinde veya yanlış yorumlandığında, ilişki üzerinde kalıcı ve zarar verici bir etkiye sahip olabilir. Dahası, kişiselleştirilmiş ve alakalı pazarlama, insanların sevdiği içerik oluşturmanın temelidir. Veri ve gizlilik mevzuatı konusundaki şüpheciliğe rağmen, araştırmalar, tüketicilerin kişiselleştirilmiş deneyimler ve teklifler karşılığında kişisel verileri paylaşmaya istekli olduğunu ve daha derin bir marka ilişkisi yarattığını göstermiştir (Baldwin, 2017; Wainwright, 2020). Adlucent 2016 araştırmasına göre, katılımcıların \%44'ü daha kişiselleştirilmiş reklamlar elde etmek için ad, adres veya eposta adresi dâhil olmak üzere çeşitli verilerini paylaşmayı kabul etmektedir (Kirkpatrick, 2016)

2020 yılında GumGum ve nöroanalitik şirketi SPARK Neuro tarafından tüketicilerin çevrimiçi medyadaki bağlamsal reklamcılığa verdikleri sinirsel ve duygusal tepkileri keşfetmek amacıyla yapılan Neuroanalytic Analysis of Contextual Ad Placement Effectiveness araştırmasında, beyin aktivitesini izlemek için EEG, duygusal tepkileri ölçmek için GSR ve yüz kodlaması ve dikkati değerlendirmek için göz izleme yöntemleri kullanılmıştır. Bulgulara göre, genel olarak bağlamsal olarak alakalı reklamlar \%43 daha fazla sinirsel etkileşim ve 2,2 kat daha iyi reklam hatırlanabilirliği ve \%10 daha fazla ilgi çekicilik oluşturmuştur. Ayrıca çalışma, bağlamsal olarak alakalı reklamların tutarlı bir şekilde daha yüksek performans sunduğu ve satın alma niyetinde istatistiksel olarak önemli bir artışa imkân sağladığı sonucuna varmıştır (GumGum \& SPARK Neuro, 2020). Öte yandan, bağlamsal reklamların diğer yararları arasında alakasız reklamları azaltmak, ürün keşfi ve daha kolay çevrimiçi alışveriş sayılabilmektedir (IAB, 2016).

\section{BAĞLAMSAL PAZARLAMADA KARŞILAŞILAN ZORLUKLAR}

Bağlamsal pazarlama, her zamankinden daha fazla müşteriye ulaşma ve Drucker'a göre daha iyi pazarlama sunmayı vaat etmektedir. Ancak aynı zamanda işletmeleri yeni risklere maruz bırakmaktadır. Bağlamsal pazarlamayla ilgili en acil zorluklardan biri gizliliktir (akt. The Economist, 2015: 4-8). Accenture tarafından 2014 yılında 2012 tüketiciyle gerçekleştirilen ankete göre, müşterilerin \%42'si işletmelerin kendilerine daha uygun teklifler sunmak için kişisel verilerini kullandıklarına inanmasına rağmen, \%39'u verilerinin satıldığını düşünmektedir. Müşterilerin \%49'u markalardan ilgili bir tekliflerle sonuçlanacaksa satın alma davranışlarının izlenmesine itiraz etmediğini belirtmektedir. Dahası, \%70'i işletmelerin bilgilerinin nasıl kullanıldığı konusunda şeffaf olmadığına inanmaktadır (https://newsroom.accenture.com/ ,2014). DMA 2018 Data Privacy Report'a göre, veri alışverişine yönelik tutumlarda kuşaksal bir değişim yaşanmaktadır. Genç tüketicilerin veri paylaşımına yönelik pragmatik veya ilgisiz bir tutum benimseme olasılığı daha yüksektir ve endişeleri 2012'den bu yana azalmıştır. (DMA, 2018). Dolayısıyla tüketiciler, 
daha iyi bir alışveriş deneyimi ile sonuçlanıyorsa verilerini paylaşmaya isteklidir. Anahtar, karşılığında değer sağlamaktır. Bağlamsal pazarlama perspektifinden, işletmelerin veri kullanımı konusunda müşterilere karşı şeffaf olması, verileri üçüncü taraflarla paylaşmaması en kritik faktörlerden biridir (Kakkar, 2017).

Bağlamsal pazarlamada karşılaşılan diğer bir zorluk, bağlamsal bilgileri etkili bir şekilde yorumlamaktır. Bunun için müşterilerin yaşamlarının daha derinden anlaşılmasını gerekmektedir (The Economist, 2015: 8). İşletmeler, hangi bilgilere sahip olduklarını ve bunları en iyi nasıl kullanacaklarını bilmelidir. Böylece, müşterileriyle alakalı kampanyalar oluşturmaları mümkün olacaktır (Kollas, 2015). Öte yandan, bağlamsal reklamcılık, bazı pazar nişlerinde maliyetli ve çoğu zaman kârsız bir pazarlama ile sonuçlanabilmektedir. Dahası, reklam bütçesi tükendikten sonra tüm reklamlar otomatik olarak kaldırılır (https://www.traff.co/, 2021). Aggarwal (2007), bağlamsal reklamcılığın diğer zorlukları arasında, kullanıcıları okumak istedikleri içerikten uzaklaştırmak, reklamın konumu içeriğin arasındaysa, kullanıcıları kesintiye uğratabilmek ve rakiplerin reklamlarının, işletmenin reklamlarıyla birlikte aynı sayfaya yerleştirilebilmesi olarak sıralamaktadır.

\section{BAĞLAMSAL PAZARLAMA STRATEJILERI}

Veri ve analitik, bağlamın sağlanmasında büyük bir rol oynar. Yapay zeka, anlamlı etkileşimleri otomatikleştirip optimize ederken, veri ve analitik iç görüler sağlar. Bu durum, ilk müşteri etkileşimini başlatan bağlamsal bir pazarlama stratejisidir (Hill, 2018). Bununla birlikte, işletmenin tüm eylemlerini, hedef kitlenin bulunduğu bağlamla ilgizengli yapması, işlemler için müşterilerden izin istemesi, bağlamsal bilgileri sorumlu bir şekilde, her zaman gizliliğe saygı göstererek kullanması ve elde edilen sonuçların müşterilerle güvene dayalı güçlü bir ilişki kurduğundan emin olması dikkat edilecek diğer unsurlar arasındadır (Scalarly, 2020). Zheng et al., (2021: 84), bağlamsal pazarlamayı uygulamanın anahtarının sıfır mesafe olduğunu belirtmektedirler. Bu, kullanıcıların taleplerini anlamak ve daha fazla teknolojiyi entegre etmek için mobil verileri kullanarak, kullanıcılarla kesintisiz bağlantı, özelleştirilmiş hizmet ve etkileşimli iletişim anlamına gelir. Sear (2014: 228), başarılı bir bağlamsal pazarlama kampanyasında, hedef kitlenin analizinin, kampanyanın gerçek zamanlı olarak izlenebilmesinin ve hızlı bir şekilde revize edilebilmesinin, çevik olmanın ve bağlamsal öğelere yoğun bir şekilde odaklanmanın önemine dikkat çekmektedir. Bununla birlikte bağlamsal bir pazarlama kampanyası planlarken göz önünde bulundurulması gereken beş önemli adımdan bahsedilebilir (Kohli, 2020):
- Alıcı kişilikleri oluşturma: Alıcı persona, bir markanın ideal müşterisinin yarı kurgusal bir temsilidir. Bir alıcı persona, ideal müşterilerin hayatlarında karşılaştıkları birkaç yaygın sorunu, çevrimiçi ortamda nerede dolaştıklarını ve onları sorunları hakkında daha fazla bilgi edinmeye neyin yönlendirdiğini özetlemelidir.

- Alıcının yolculuğunun haritasını çıkarma: Alıcının yolculuğunun haritasını çıkarmak, alıcı kişiliklerine başka bir katman ekler. Bu, reklamcılık çabalarını hedef kitlenin belirli zihniyetine, ilgi alanlarına ve davranışlarına, alıcı yolculuğunun hangi aşamasına ait olduklarına göre daha iyi hizalamaya yardımcı olur.

- Rekabeti analiz etme: Bunun için ideal müşterilerin hangi web sitelerini ziyaret ettiğini bulmak gerekir. İdeal müşterilerin bilgilerinin nerede bulduğunu bilmek ve anlamak, reklamları onları görme ve harekete geçme olasılığı en yüksek olan kişilere doğru şekilde hedeflemek için çok önemlidir.

- Konuyu ve anahtar kelimeleri araştırma: Bunlar, üçüncü adımda belirlenilen Web sitelerini bulmak için ideal müşterilerin kullandığı anahtar kelimelerdir. Yüksek arama hacmine ve nispeten düşük rekabete sahip alakalı anahtar kelimeleri bulmaya yardımcı olması için Google'ın Anahtar Kelime Planlayıcı kullanılabilir.

- Bağlamsal bir reklam oluşturma: Son adım, içeriğe dayalı reklam kampanyasını oluşturmak ve başlatmaktır.

Bağlamsal hedefleme, reklamları Görüntülü Reklam Ağı'nın parçası olan sitelerde, uygulamalarda ve web sayfalarında görüntülemek için kullanabilecek bir yöntemdir. Google Görüntülü Reklam Ağı, müşterilere bir YouTube videosunu izlerken, web sitelerine göz atarken, Gmail hesaplarını kontrol ederken ya da mobil cihazlarında ve uygulamalarında ulaşmaya yardımcı olur. Ayrıca, doğru kitleyi bulmayı sağlar. Bağlamsal hedefleme, reklamları en alakalı sitelerle eşleştirmek için seçilen konuları veya anahtar kelimeleri kullanır (Kloefkorn, 2018). İşletmeler, bağlamsal kampanyaları için bir anahtar kelime listesi oluştururken kelimelerin eş anlamlılarını veya tahminlerini kullanmak yerine geniş, tematik bir liste oluşturmayı tercih edebilir. Bu gereklidir çünkü bağlamsal reklamcılık, yalnızca eşleşen anahtar kelimelerle değil, benzer içerik için sayfaları tarayarak çalışır. Eşanlamlı anahtar kelimelerin bir listesi, reklamın yalnızca anahtar kelimenin karşılık geldiği alakalı web sitelerinde görüntülendiği anlamına gelir. Bununla birlikte, tematik bir liste, tüm alanın temsil edildiği sayfalara götürecek ve daha geniş bir müşteri kitlesine ulaşmaya yardımcı olacaktır (Duff, 2021). 


\section{SONUÇ}

Bağlamsal pazarlama, nispeten yeni ancak işletmeler tarafından hızla benimsenmekte olan bir pazarlama aracıdır. Günümüzde çok sayıda işletme, bağlamsal pazarlamanın avantajlarının farkına varmakta ve bağlamsal pazarlama stratejilerini kullanmaya başlamaktadır. Bağlamsal pazarlama, doğru bilgileri, doğru kişilere ve doğru zamanda sağlama temeline dayanmaktadır. Dahası, ürünleri/hizmetleri belirli tüketiciler için kişiselleştirmektedir. Tüketiciler, giderek daha fazla kişiselleştirilmiş deneyim ve/veya ürün/hizmet talep ettiklerinden bağlama dayalı reklamlar, potansiyel müşterileri aktif müşterilere dönüştürmek ve uzun dönemli müşteri ilişkileri geliştirmek için oldukça uygun bir yoldur.

Bağlamsal pazarlama, işletmelere birçok avantaj sunmaktadır. Bunlar arasında, geleneksel reklamların tüketicileri kesintiye uğratan doğasını yok etmek, özelleştirilmiş deneyimler, sadık müşteriler ve marka farkındalığı oluşturmak, çapraz ve ek satış fırsatları, müşterilerin tekrar satın alma olasılıkları arttırmak, daha etkili hedefleme ve düşük maliyet bulunmaktadır. Bununla birlikte, bağlamsal pazarlama gizlilik ve müşteri verilerini doğru yorumlayabilme zorluklarını beraberinde getirmektedir. Öte yandan literatürde bağlamsal pazarlama ile yapılan ampirik ve teorik çalışmalar incelendiğinde, bağlamsal pazarlamanın henüz emekleme döneminde olduğunu söylemek yanlış olmayacaktır. Literatürde bağlamsal pazarlamayla ilgili çok daha fazla araştırmaya intiyaç duyulsa da, müşteri deneyimlerinde kişiselleştirmenin ve çevrimiçi davranışı kesintiye uğratmadan kullanıcıların dikkatini çekmenin önemi göz önüne alındığında, uygun maliyetiyle bağlamsal pazarlama işletmeler için tavsiye edilmektedir.

\section{KAYNAKÇA}

Aggarwal, A. (2007). The Good and the Bad of Contextual Advertising, https://ezinearticles.com/?The-GoodAnd-The-Bad-Of-Contextual-

Advertising\&id=530838, Erişim tarihi: 14.04.2021

Armano, G., Giuliani, A. \& Vargiu, E. (2011). Studying the Impact of Text Summarization on Contextual Advertising, 22nd International Workshop on Database and Expert Systems Applications, IEEE, 172-176.

Baldwin, C. (2017). How Contextual Marketing Will Help Your

Brand,https://marketingtechnews.net/news/2017/ may/15/how-contextual-marketing-will-help-yourbrand/, Erişim Tarihi: 20.05.2021

Beales, H. (2010). The Value of Behavioral Targeting,
Network Advertising Initiative, 1.

Berry, S. (2019). What Is Contextual Targeting? (And Why Does It Even Matter?), https://www.webfx.com/blog/marketing/contextualtargeting/, Erişim Tarihi: 20.05.2021

Broder , A., Fontoura, M., Josifovski, V. \& Riedel, L. (2007). A Semantic Approach to Contextual Advertising, Proceedings of the 30th Annual International ACM SIGIR Conference on Research and Development in Information Retrieval, 559-566.

Broughton, M. (2019). Predictions 2020: The Rise of Contextual Advertising, https://www.exchangewire.com/blog/2019/12/18/p redictions-2020-the-rise-of-contextual-advertising/ , Erişim Tarihi: 14.04.2021

Chen, G. \& Kotz, D. (2000). A Survey of Context-Aware Mobile Computing Research, Computer Science Technical Report TR2000-381, https://digitalcommons.dartmouth.edu/cs_tr/177, 116.

Chun, K., Song, J., Hollenbeck, C., \& Lee, J. (2014). Are contextual advertisements effective? The moderating role of complexity in banner advertising. International Journal of Advertising, 33(2), 351-371.

Clevinger, A. (2021). What is Targeting: Definition and Types, https://snov.io/glossary/targeting/ , Erişim Tarihi: 20.05.2021

Conti, M., Nguyen, V. \& Crispo, B. (2010). CRePE: ContextRelated Policy Enforcement for Android?, International Conference on Information Security, Springer, Berlin, Heidelberg, 331-345.

Coutaz, Y., Crowley, J., Dobson, S. \& Garlan, D. (2005). Context is Key, Communications of the ACM, 48(3), 4953.

Dey, A. (2001). Understanding and Using Context, Personal and Ubiquitous Computing, 5(1), 4-7.

DMA (2018). Data Privacy: What the Consumer Really Thinks, https://dma.org.uk/uploads/misc/5a857c4fdf846data-privacy---what-the-consumer-really-thinksfinal_5a857c4fdf799.pdf ,Erişim Tarihi: 20.05.2021

Duff, J. (2021). 7 Contextual Advertising Tips to Power Your Campaign, https://www.thomsondata.com/article/contextualadvertising-tips.php, Erişim Tarihi: 20.05.2021

Fan, T.-K. \& Chang, C.-H. (2009). Blogger-Centric Contextual Advertising, CIKM '09: Proceedings of the 18th ACM Conference on Information and Knowledge Management, 1803-1806. 
GumGum \& SPARK Neuro. (2020). Cognitextual: A Neuroanalytic Study of Contextual Ad Effectiveness, https://insights.gumgum.com/hubfs/Advertising/A dvertising\%20Newsletter/Volume\%20IV/Cognitextu al\%20Study\%20FULL\%20GUIDE\%20(1).pdf, Erişim Tarihi: 20.05.2021

Hemdev, A. (2019). The Beginner's Guide to 6 Types of Ad Targeting, https://blog.zyp.tv/types-of-ad-targeting, Erişim Tarihi: 20.05.2021

Hill, C. (2018). Why Marketers Need A Contextual Marketing Strategy, https://www.veracentra.com/blog/contextualmarketing-strategy/, Erişim Tarihi: 20.05.2021

http://grow.segment.com/Segment-2017-PersonalizationReport.pdf (2017). The 2017 State of Personalization Report, Erişim Tarihi: 20.05.2021

https://dictionary.cambridge.org/dictionary/english/targe ting (2021). Targeting, Erişim Tarihi: 20.05.2021

https://insights.gumgum.com/hubfs/ContextualAdvertising-the-new-frontier-final-guide.pdf (2018). Contextual Advertising: The New Frontier, Erişim Tarihi: 14.04.2021

https://newsroom.accenture.com/news/eighty-percentof-consumers-believe-total-data-privacy-no-longerexists-accenture-survey-finds.htm (2014). Eighty Percent of Consumers Believe Total Data Privacy No Longer Exists, Erişim Tarihi: 14.04.2021

https://www.criteo.com/blog/4-reasons-contextualtargeting-is-trending/ (2020). 4 Reasons Contextual Targeting Matters More than Ever, Erişim Tarihi: 14.04.2021

https://www.epsilon.com/us/about-us/pressroom/newepsilon-research-indicates-80-of-consumers-aremore-likely-to-make-a-purchase-when-brandsoffer-personalized-experiences (2018). New Epsilon Research Indicates $80 \%$ of Consumers are More Likely to Make a Purchase When Brands Offer Personalized Experiences, Erişim Tarihi: 14.04.2021

https://www.knorex.com/blog/articles/contextualtargeting (2021). Contextual Targeting 101: How To Use Relevance To Drive Better Engagement Without Cookies, Erişim Tarihi: 20.05.2021

https://www.marketing-schools.org/types-ofmarketing/contextual-marketing/\#section-1 (2021). Contextual Marketing, Erişim Tarihi: 20.05.2021

https://www.marketsandmarkets.com/MarketReports/contextual-advertising-market165798900.html (2018). Contextual Advertising
Market, Erişim Tarihi: 14.04.2021

https://www.reportlinker.com/p05798251/Global-

Contextual-Advertising-

Industry.html?utm source=GNW (2021). Global Contextual Advertising Industry, Erişim Tarihi: 20.05.2021

https://www.thinkwithgoogle.com/future-ofmarketing/creativity/marketing-personalizationstatistics/ (2017). Marketing-Personalization Statistics, Erişim Tarihi: 14.04.2021

https://www.traff.co/en/blog/contextual-advertising (2021). Contextual advertising, Erişim Tarihi: 20.05.2021

IAB. (2016). The Value of Targeted Advertising to Consumers, https://www.iab.com/wpcontent/uploads/2016/05/Value-of-Targeted-Ads-toConsumers2.pdf, Erişim Tarihi: 14.04.2021

Jain, R. (2021). What is Contextual Marketing, https://www.profitablepopularity.com/what-iscontextual-marketing/?cn-reloaded=1, Erişim Tarihi: 20.05.2021

Kakkar, V. (2017). Why Contextual Marketing Is The Next Big Wave In Customer Conversion. https://conversionsciences.com/contextualmarketing/ , Erişim Tarihi: 14.04.2021

Kirkpatrick, D. (2016). Study: 71\% of Consumers Prefer Personalized Ads, https://www.marketingdive.com/news/study-71-ofconsumers-prefer-personalized-ads/418831/ , Erişim Tarihi: 14.04.2021

Kloefkorn, S. (2018). Targeting Strategies: Need to Get Contextual, https://keomarketing.com/insights/targetingstrategies-get-contextual/ , Erişim Tarihi: 14.04.2021

Kohli, A. (2020). What Is Contextual Targeting? How It Works (in 5 Steps), https://www.business.com/articles/5steps-of-contextual-targeting/ , Erişim Tarihi: 14.04.2021

Kollas, S. (2015). How Contextual Marketing Affects Your Strategy, http://www.experian.com/blogs/marketingforward/2015/10/12/how-contextual-marketingaffects-your-strategy/ , Erişim Tarihi: 14.04.2021

Lee, T. \& Jun, J. (2007). Contextual Perceived Value? Investigating the Role of Contextual Marketing for Customer Relationship Management in a Mobile Commerce Context, Business Process Management Journal, 13 (6), 798-814. 
Lian, S., Cha, T. \& Xu, Y. (2019). Enhancing Geotargeting with Temporal Targeting, Behavioral Targeting and Promotion for Comprehensive Contextual Targeting, Decision Support Systems, 117, 28-37.

Liu, P., Azimi, J. \& Zhang, R. (2014). Automatic Keywords Generation for Contextual Advertising, Proceedings of the 23rd International Conference on World Wide Web, 345-346.

Luo, X. (2003). The Performance Implications of Contextual Marketing for Electronic Commerce, Journal of Database Marketing, 10(3), 231-239.

Luo, X. ve Seyedian, M. (2003). Contextual Marketing and Customer-Orientation Strategy for E-Commerce: An Empirical Analysis, International Journal of Electronic Commerce, (8)2, 95-118.

Microsoft \& Adobe (2018). Five Daunting Sales and Marketing Gaps, http://info.microsoft.com/rs/157GQE-382/images/EN-CNTNT-eBook-AzureDynamics-Adobe-Five-Daunting-Sales-andMarketing-Gaps.pdf, Erişim Tarihi: 14.04.2021

Niu, X., Ma, J. \& Zhang, D. (2009). A Survey of Contextual Advertising, 2009 Sixth International Conference on Fuzzy Systems and Knowledge Discovery.

Pak, A. \& Chung, C.-W. (2010). A Wikipedia Matching Approach to Contextual Advertising, World Wide Web, 13, 251-274.

Pandey, S., Aly, M., Bagherjeiran, A., Hatch, A., Ciccolo, P., Ratnaparkhi, A. \& Zinkevich, M. (2011). Learning to Target: What Works for Behavioral Targeting, CIKM '11: Proceedings of the 20th ACM International Conference on Information and Knowledge Management, 1805-1814.

Ping, Y. (2019). Contextual Marketing in the Mobile Internet Environment: A Literature Review and Prospects, Foreign Economics \& Management, 41(5), 3 - 16.

Radhika, V., Thottungal, A. \& Nizar, A. (2016). An Enhanced Model for Behavioral Targeting in Online Advertising. International Conference on Data Science and Engineering (ICDSE).

Rayport, J. \& Sviokla, J. (1994). Managing in the Marketspace. Harvard Business Review, https://hbr.org/1994/11/managing-in-themarketspace\#. , Erişim Tarihi: 14.04.2021

Rivard, J. (2017). The True Power of Contextual Marketing. https://marketinginsidergroup.com/contentmarketing/true-power-contextual-marketing/ Erişim Tarihi: 14.04.2021

Samat, S., Acquisti, A. \& Babcock, L. (2017). Raise the
Curtains: The Effect of Awareness About Targeting on Consumer Attitudes and Purchase Intentions, Proceedings of the Thirteenth Symposium on Usable Privacy and Security (SOUPS 2017).

Scalarly. (2020). Contextual Marketing: Little Marketing Book, https://scalarly.com/marketingbook/wiki/contextual-marketing-2/ , Erişim Tarihi: 14.04.2021

Sear, D. (2014). Decca Tests Contextual Mobile Marketing. Journal of Direct, Data and Digital Marketing Practice, $15,226-228$.

Shukla, P. (2009). Impact of Contextual Factors, Brand Loyalty and Brand Switching on Purchase Decisions, Journal of Consumer Marketing, 26 (5), 348-357.

The Economist. (2015). Beyond Personalisation - The Challenges of Contextual Marketing. https://eiuperspectives.economist.com/marketing/b eyond-personalisation-challenges-contextualmarketing/white-paper/beyond-personalisationchallenges-contextual-marketing, Erişim Tarihi: 14.04.2021

Vanessa, N., \& Japutra, A. (2017). Contextual Marketing Based on Customer Buying Pattern in Grocery ECommerce: The Case of Bigbasket.com (India). Asean Marketing Journal, 9(1), 56-67.

Wainwright, C. (2020). What Is Context Marketing, and Why It Matters, https://blog.hubspot.com/blog/tabid/6307/bid/3389 4/what-s-the-deal-with-this-whole-contextmarketing-thing.aspx, Erişim Tarihi: 14.04.2021

Wise, D. (2019). The Five Changes Shaping the Future of Contextual Advertising, https://www.thedrum.com/industryinsights/2019/11 /21/the-five-changes-shaping-the-future-contextualadvertising, Erişim Tarihi: 14.04.2021

Wojdynski, B. \& Bang, H. (2016). Distraction Effects of Contextual Advertising on Online News Processing: An Eye-Tracking Study, Behaviour \& Information Technology, 35(8), 654-664.

Yan, J., Liu, N., Wang, G., Zhang, W., Jiang, Y. \& Chen, Z. (2009). How much can Behavioral Targeting Help Online Advertising?, Proceedings of the 18th international conference on World Wide Web, 261270.

Zerr, K., Albert, R. \& Forster, A. (2017). Context Sensitive Digital Marketing - A Conceptual Framework Based on the Service Dominant Logic Approach, International Conference on $\mathrm{HCl}$ in Business, Government, and Organizations, Springer, Cham, 298-312. 
Zheng, X., Lin, F. \& Cai, X. (2021). Exploration of Contextual Marketing Model Based on Mobile Apps, 6th Annual International Conference on Social Science and
Contemporary Humanity Development (SSCHD 2020), Atlantis Press, 81-85.

(c) (i) $\$$

(C) 2020 \& 2021 by the authors. Submitted for possible open access publication under the terms and conditions of the Creative Commons Attribution (CC BY NC) license.

(https://creativecommons.org/licenses/by-nc/4.0/). 